\title{
Three brothers with algodystrophy of the hip
}

\author{
J. A LBERT AND H. OTT \\ From the Department of Rheumatology, La Chaux-de-Fonds Hospital, Switzerland
}

SUMMARY We describe the clinical features of algodystrophy of the hip in 3 brothers, probably the first familial presentation of this disease to be reported. The symptoms and evolution of the disease are as usually described. The familial presentation suggests a genetic predisposition. HLA typing showed an identity of antigenic formula in the 3 brothers, a rare coincidence.

Algodystrophy of the hip is a rare disease. In 1981 Doury et al. ${ }^{1}$ reviewed 160 reported cases but suggested that the condition may be more prevalent because it is often misdiagnosed. In its classic and complete form the disease is frequently unilateral, predominantly on the left. ${ }^{12}$ Males are usually affected in their $40 \mathrm{~s}^{1-3}$ and women during pregnancy. ${ }^{45}$ It begins with a sudden or progressive onset of pain in the groin, the trochanteric region, the thigh, or the knee. There is often a limp and a functional weakness of the affected limb with paradoxical slight pain. ${ }^{6}$ Three to 6 weeks $^{13}$ after the onset of symptoms $x$-rays may show a diffuse or spotty regional osteoporosis of the femoral head and acetabulum. Repair takes 4 to 7 months ${ }^{367}$ The erythrocyte sedimentation rate (ESR) and acute-phase reactants are usually within normal limits.

The condition sometimes follows trauma and becomes a form of reflex dystrophy, but usually no precipitating factors are found. ${ }^{16}$ The succession of pathological events which leads to the syndrome is not well known. It is thought that local 'circulatory disturbances' of neurosympathetic origin might play a major role in the bone remodelling. ${ }^{4}{ }^{8}$ Lequesne ${ }^{3}$ in 1968 was the first who employed the term "transient osteoporosis of the hip.' After Lequesne a series of French publications $s^{1367910}$ arrived at a consensus that the disorder is probably the equivalent of a reflex dystrophy (Südeck type) at the hip joint. They coined the term 'algodystrophy' in preference to 'osteoporosis, stating that certain forms of the disease are inapparent radiologically, being diagnosed by technetium bone scanning, which shows increased uptake due to active bone resorption and apposition in the trabeculae. ${ }^{1910}$

We report here the development of algodystrophy of the hip in 3 brothers.

Accepted for publication 6 October 1982 .

Correspondence to Dr H. Ott, Department of Rheumatology, 2300 Hôpital de La Chaux-de-Fonds, Switzerland.

\section{Case reports}

The 3 brothers, who had been living separately for more than 10 years in Switzerland, were born in a village in south-west Italy.

\section{PATIENT 1}

In March 1980 the patient, aged 39, without previous trauma complained of limping and of moderate pain in the right inguinal and trochanteric region which was relieved by anti-inflammatory drugs. There was a right-leg limp and hypotonia of the right quadriceps. External rotation was slightly reduced; passive internal rotation and combined flexion-abductionrotation were painful. Mild osteoporosis of the right femoral head was present on a pelvic film in April 1980 (Fig. 1) but absent in June. In November 1981 a similar painful episode with limping affected the left hip. Range of motion was not reduced, but the left trochanter was tender. Monthly $x$-rays were normal over 6 months. A bone scan in December 1981 showed a target-shaped pattern of increased uptake

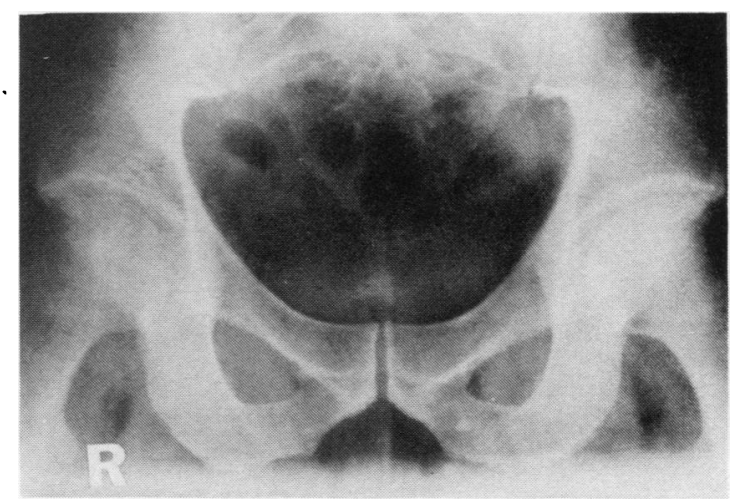

Fig. 1 Case 1. Osteoporosis of the right femoral head in April 1980. 
maximal in the centre of the left femoral head. This decreased in February and April 1982 (Fig. 2).

$\mathrm{He}$ was treated with $100 \mathrm{U}$ of salmon clacitonin subcutaneously, at first 5 days a week for 1 month, then 3 days a week for the next month. Pain disappeared after the tenth injection. Physical therapy was then started.

\section{PATIENT 2}

In October 1980, when he was 41 , this patient suddenly felt pain in the left groin on movement. It reached its peak in 2 days and caused a limp for 3 weeks. When the patient was referred to us in

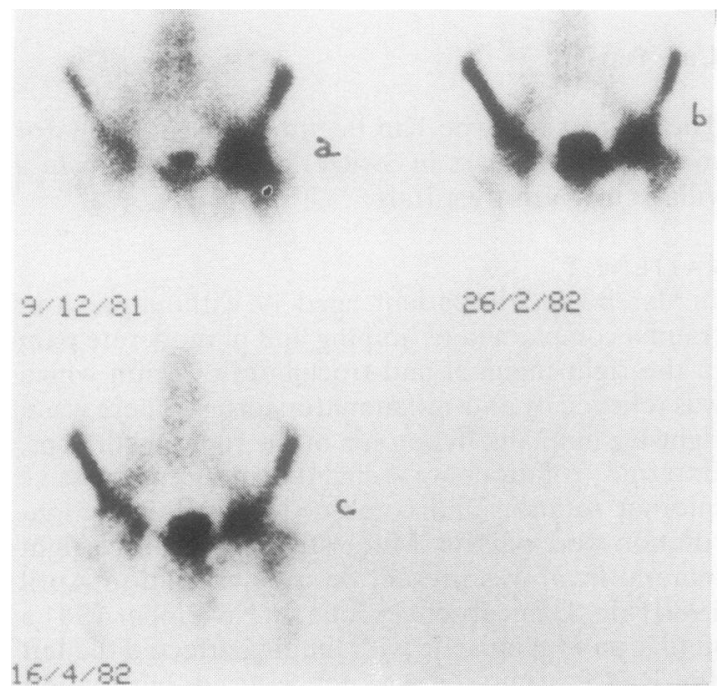

Fig. 2 Case 1. Bone scan showing (a) increased uptake of the left femoral head in December 1981. This decreased on controls in (b) February and (c) April 1982.

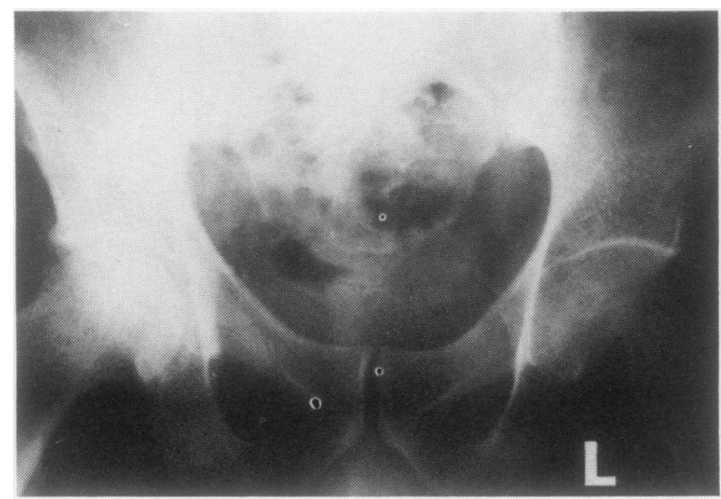

Fig. 3 Case 2. 'Phantom' appearance of the left femoral head in November 1980.
November 1980 there was improvement, with no impairment in the range of movement in the left hip. The left inguinal fold and trochanter were tender, and internal rotation was painful. $X$-rays (Fig. 3) showed marked osteoporosis of the whole left femoral head, which persisted till March 1981. Tomography in December 1980 confirmed the integrity of the joint space.

In June 1982 a similar painful episode affected the right thigh distally. A bone scan showed increased uptake in the right knee (Fig. 4).

PATIENT 3

In December 1978 the third brother, aged 30, rapidly developed pain in the right hip radiating to the knee

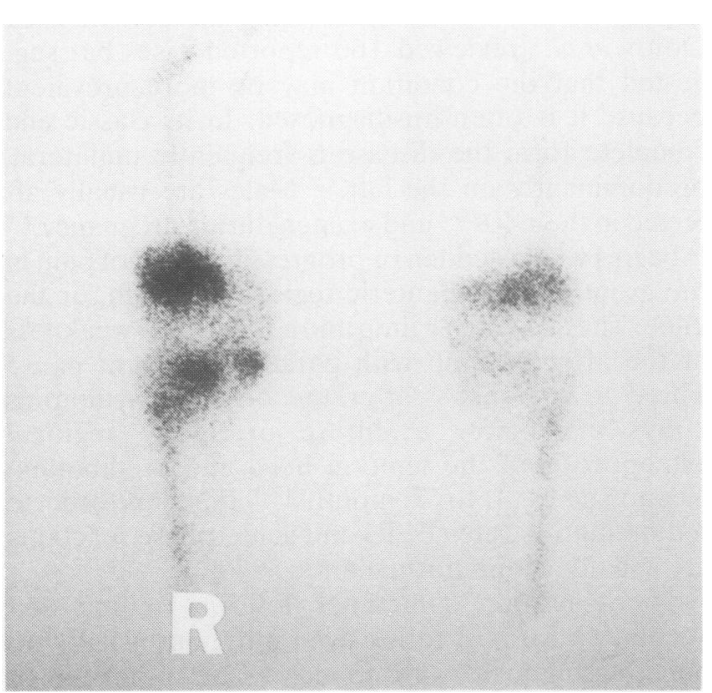

Fig. 4 Case 2. Increased uptake of the right knee in June 1982.

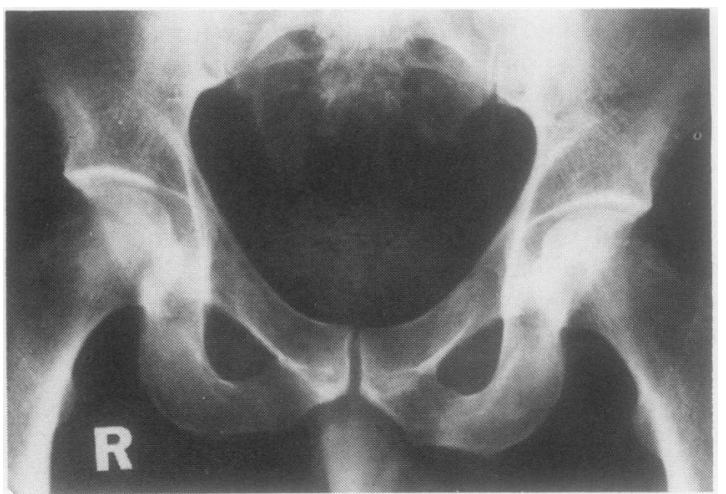

Fig. 5 Case 3. Osteoporosis of the upper external quarter of the right femoral head in March 1979. 


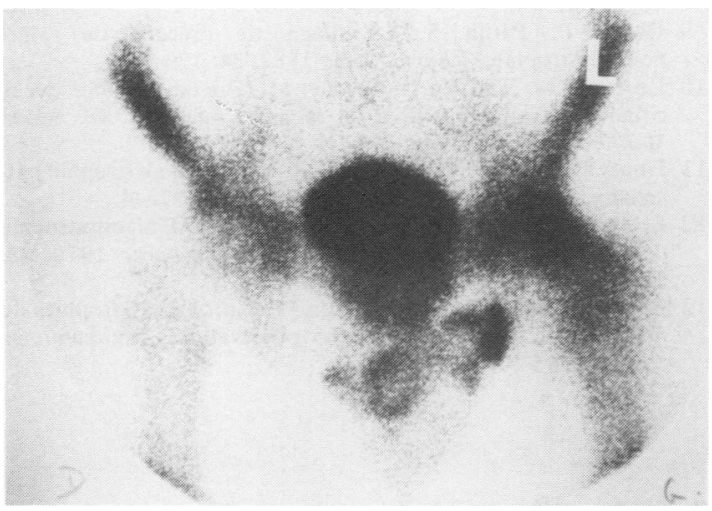

Fig. 6 Case 3. Bone scan: increased uptake in the left femoral head in June 1982.

and began limping. After 4 months of bed rest his condition spontaneously improved.

In September 1981, when we first saw the patient, there was $1.5 \mathrm{~cm}$ atrophy of the right quadriceps. $X$-rays in March 1979(Fig. 5) showed osteoporosis in the upper external quarter of the femoral head without any alteration of the interarticular line. This demineralisation remained localised until its disappearance on subsequent films. Retrospectively we diagnosed transient osteoporosis of the hip. In April 1982 the pain and limping recurred on the left side, with a feeling of heaviness and weakness of the thigh. Mobility of the left hip was normal, but movement triggered pain over the trochanter. In June 1982 a bone scan showed increased uptake in the left femoral head (Fig. 6). He was treated by salmon calcitonin with good clinical results.

\section{LABORATORY FINDINGS}

The following tests were normal in all 3 subjects: uric acid, erythrocyte sedimentation rate, complete blood count, fasting blood sugar, thyroid hormone levels, cholesterol, triglyceride, serum lipid electrophoresis, and platelet aggregation. Hydroxyproline excretion was normal.

HLA grouping showed an identical formula: A 1-30 or 31; B 8-37; BW 4-6; DR 7-X; MT 3-1,2 in all 3 subjects (National Laboratory of Swisstransplant, Geneva).

\section{Discussion}

None of the patients gave any history of trauma, fever, or systemic disease. We failed to find any of the factors usually predisposing to algodystrophy: diabetes, hyperlipidaemia, anxiety, or depression. They had not been taking drugs before the episodes. There was no evidence of cardiac, endocrine, pulmonary, or neurological disease. Another striking fact was the identity of the HLA formula in all 3 brothers, a rare coincidence.

The relationship between HLA type and algodystrophy has not been well documented, and its importance as a risk factor in this condition remains unknown. ${ }^{1}$

It is noteworthy that our patients presented different radiological aspects of the disease. Patient 1 during the first episode in October 1980 developed a mild osteoporosis of the right femoral head, while in November 1981 the $x$-rays showed what Lequesne $e t$ $a l^{10}$ define as 'infra-radiological' form, in which successive films do not show hyperlucency of the bony structures, the main evidence for a neurosympathetic disorder being the increased uptake on the bone scan (Fig. 2). Our second case showed the classic $x$-ray picture of the disease with a 'phantom' appearance of the femoral head in November 1980 (Fig. 3), followed in June 1982 by involvement of the right knee (Fig. 4). Patient 3, in March 1979 (Fig. 5), showed a highly localised algodystrophy,,$^{160-12}$ a form in which bone resorption affects only a part of the femoral head without secondary extension during the entire course of the disease. The second attack in April 1982 (Fig. 6) remained 'infra-radiological' until June 1982.

\section{CONCLUSION}

Algodystrophy can affect both hips either simultaneously or in succession. Patients 1 and 3 presented the latter, alternating form, seen in 20 to $30 \%$ of cases, ${ }^{16}$ in which the second 'circulatory disturbance' occurs several months to several years ${ }^{1}$ after the first and affects the previously spared hip. Bone resorption of the hip may be followed by involvement of the lower limbs, ${ }^{17}$ as in our second case. Why algodystrophy in any location rarely affects the same joint twice is unknown. ${ }^{13}$ It would seem that involvement of a joint protects it from further episodes. This familial presentation of algodystrophy invites us to consider the possible existence of a genetic factor in the development of the disease.

We are grateful to Dr Yves Dirheimer and Professor P. Doury for their constructive comments, Dr Michel Jeannet for his technical assistance, and Professor René Lagier for his advice.

\section{References}

1 Doury P, Dirheimer Y, Pattin S. Algodystrophy: diagnosis and therapy of a frequent disease of the locomotor apparatus. New York: Springer, 1981: 18-38.

2 Rosen R A. Transitory demineralization of the femoral head. Radiology 1970; 94: 509-12.

3 Lequesne M. Transient osteoporosis of the hip: a nontraumatic variety of Südeck's atrophy. Ann Rheum Dis 1968; 27: 463-71. 
4 Curtis P H, Kincaid W E. Transitory demineralization of the hip in pregnancy: a report of three cases. J Bone Joint Surg 1959; 41A: 1327-33.

5 Valenzuela F, Aris H, Jacobelli S. Transient osteoporosis of the hip. J Rheumatol 1977; 4: 59-64.

6 Lequesne M, Mauger B. L'algodystrophie décalcifiante de la hanche. Rhumatologie 1979; 31: 369-76.

7 Schiano A, Eisinger J, Acquaviva P C. Les algodystrophies. Laboratoires Armour Montagu: Levallois-Perret, 1977: 29-32.

8 Swezey R L. Transient osteoporosis of the hip, foot and knee. Arthritis Rheum 1970; 13: 858-68.
9 Doury P, Pattin S. Le diagnostic précoce des algoneurodystrophies. Rhumatologie 1982; 34: 129-32.

10 Lequesne M, Spartien O, Fauchet M. L'algodystrophie 'décalcifiante' infra-radiologique du membre inférieur. Rev Rhum Mal Osteoartic 1981; 48: 423-30.

11 Doury P, Delahaye R P, Granier R, et al.L'algodystrophie parcellaire. Rev Rhum Mal Osteoartic 1979; 46: 37-44.

12 Lequesne M, Kerboull M, Boasson M, et al. L'algodystrophie décalcifiante partielle. Rev Rhum Mal Osteoartic 1979; 46: 111-21.

13 Renier J C, Bregeon Ch, Boasson M, et al. Algodystrophies du membre inférieur. Etude de 65 observations. Rhumatologie 1973; 23: 55-9. 